\title{
Perancangan Sistem Pengarsipan Surat Masuk dan Surat Keluar pada Desa Kampung Besar Menggunakan Metode Alphabetical Filing dan Chronology System
}

\author{
Noer Azni Septiani' ${ }^{1}$, Deden Haitami ${ }^{2}$ \\ ${ }^{1,2}$ Universitas Bina Sarana Informatika \\ Kampus Kramat 98 Jl.Kramat Raya No.98, Senen, Jakarta Pusat 10450 \\ Correspondence email: noer.azni@bsi.ac.id
}

\begin{abstract}
Abstrak. Arsip merupakan salah satu sumber informasi yang memiliki fungsi penting untuk menunjang proses kegiatan administrasi dan manajemen sebuah instansi. Semua kegiatan yang dilakukan oleh instansi tersebut, baik itu berupa proposal, surat- menyurat maupun dokumen-dokumen lain akan menjadi arsip. Informasi yang terekam tersebut merupakan bukti dan dokumentasi atau memori bagi instansi yang bersangkutan. Pada Desa Kampung Besar Teluknaga sistem pengarsipan surat yang berjalan masih belum terkomputerisasi, sehingga dalam sistem tersebut terdapat beberapa masalah dalam keakuratan data. Penelitian ini bertujuan membuat sistem pengelolaan surat untuk meningkatkan efisiensi pengambilan kembali dalam rangka kegiatan investigasi maupun referensi kedinasan. Metode Alphabetical Filing dan Chronology System digunakan dalam perancangan system karena sederhana dan mudah diimplementasikan, pengarsipan surat pada desa kampung besar teluknaga menggunakan program dekstop yang mudah digunakan dalam sistem tersebut juga mudah dalam hal penggunaan dan perawatan. Selain mempermudah proses pengarsipan surat sistem tersebut juga mempermudah pegawai dalam proses pembuatan laporan dan pencarian data. Sistem usulan tersebut diharapkan mempu memperbaiki sistem yang sedang berjalan saat ini sehingga mampu membuat sistem pengarsipan surat masuk dan surat keluar pada Desa Kampung Besar Teluknaga menjadi lebih efekif dan efisien.
\end{abstract}

Kata kunci: Alphabetical Filing; Arsip; Chronology System

\begin{abstract}
The archive is one source of information that has an important function to support the process of administration and management of an agency. All activities carried out by the agency, whether in the form of proposals, correspondence or other documents will be archived. The recorded information is evidence and documentation or memory for the agency concerned. In the village of Kampung Besar Teluknaga the letter filing system that is running is still not computerized, so that in the system there are some problems in the accuracy of the data. This study aims to create a letter management system to improve the efficiency of retrieval in the context of investigative and official reference activities. The Alphabetical Filing and Chronology System method is used in system design because it is simple and easy to implement, archiving letters to large villages in the bay using a desktop program that is easy to use in the system is also easy in terms of use and maintenance. In addition to simplifying the process of archiving letters, the system also facilitates employees in the process of making reports and searching data. The proposed system is expected to improve the current system so that it can make the filing system of incoming and outgoing letters in the village of Kampung Besar Teluknaga more effective and efficient.
\end{abstract}

Keywords: Alphabetical Filing; Archive; Chronology System

\section{PENDAHULUAN}

Surat menyurat merupakan kegiatan yang sangat penting dalam mengelola sistem administrasi pada sebuat organisasi dan perusahanan (Mayasari et al., 2020). Desa merupakan suatu wilayah yang ditempati oleh sejumlah penduduk yang diberi keluasan untuk dapat berkreasi dalam rangka mengatur dan menyelenggarakan urusan rumah tangganya sendiri sesuai dengan adat istiadat, kebutuhan, dan aspirasi masyarakat dalam kehidupan sehari-hari. Sedangkan Administrasi merupakan kegiatan ketatausahaan yang meliputi kegiatan catat-mencatat, surat-menyurat, pembukuan dan pengarsipan surat serta hal-hal lain yang dimaksud untuk menyediakan informasi serta mempermudah memperoleh informasi kembali jika dibutuhkan. Arsip adalah rekaman kegiatan atau peristiwa dalam berbagai bentuk dan media yang harus dapat dikelola dengan baik dan teliti (Basri \& Devitra,
2017). Untuk peningkatan mutu pelayanan maka dibutuhkan suatu sistem pelayanan pada kelurahan sehingga mempermudah kinerja penyelenggara pelayanan di kelurahan dan meningkatkan kualitas pelayanan aparat yang menjadi sistem terkomputerisasi serta mempermudah pendataan/pengarsipan data administrasi warga (Wati \& Despahari, 2018). Arsip merupakan salah satu sumber informasi yang memiliki fungsi penting untuk menunjang proses kegiatan administrasi dan manajemen sebuah instansi (Simangunsong, 2018). Jumlah surat yang dibuat dan diterima secara administratif yang tidak sedikit mengakibatkan data pencarian tidak efiesien dalam hal waktu dan cukup menghabiskan energi apabila dilakukan dengan menggunakan cara manual (Farell et al., 2018). Fungsi kearsipan yaitu untuk menyajikan suatu informasi dan data secara cepat dan tepat kepada yang membutuhkan. Sistem pengarsipan dapat di bilang 
baik jika waktu penyimpanan atau pengarsipan yang di butuhkan bisa ditemukan kembali dengan cara tepat dan cepat, sehingga dibutuhkan kerapihan dalam penataan arsip yang begitu efektif dan sistematis, dikarenakan sistem pengarsipan tidak jauh melakukan kegiatan penataan pengarsipan dan juga kegiatan lainnya seperti penemuan Kembali (Mulyati et al., 2020). Semua kegiatan yang dilakukan oleh instansi tersebut, baik itu berupa proposal, surat-menyurat maupun dokumendokumen lain akan menjadi arsip. Pengelolaan surat masuk dan surat keluar merupakan salah satu tugas yang harus dijalankan agar proses layanan menjadi maksimal (Pawana et al., 2014). Informasi yang terekam tersebut merupakan bukti dan dokumentasi atau memori bagi instansi yang bersangkutan. Surat merupakan salah satu media komunikasi yang sangat penting dalam suatu instansi, perusahaan maupun bentuk organisasi yang lain, baik untuk berkomunikasi dengan pihak- pihak secara eksternal maupun internal. Setiap hal yang menyangkut kegiatan organisasi yang bersifat resmi selalu diwujudkan dalam bentuk surat (Anggraeni \& Iriani, 2013). Surat keluar ialah surat yang lengkap (bertanggal, bernomor, berstempel dan telah ditandatangani oleh pejabat yang berwenang) yang dibuat oleh instasi atau lembaga lain Permasalahan yang terjadi didalam pemerintahan desa kampung besar teluknaga dan cukup mendapat perhatian adalah tentang proses pengarsipan surat masuk dan surat keluar yang masih di lakukan secara manual,mulai dari proses penerimaan surat, pencatatan surat masuk dan surat keluar, serta penyimpanan data surat masuk dan surat keluar yang hanya pada file kerja saja, hal ini akan mengakibatkan keterlambatan dalam pencarian data-data surat serta proses pembuatan laporan surat yang tidak efektif. Oleh karena itu penulis ingin membangun sebuah rancangan sistem, yaitu perancangan sistem pengarsipan surat masuk dan surat keluar pada desa kampung besar teluknaga.

Permasalahan yang terjadi Dalam menyimpan data-data masih sangat kurang dalam penataannya dan kurang efektif dikarenakan tidak terdapat tempat untuk penyimpanan sebuah data yang terintegrasi dan baik (Mulyati et al., 2020).

Tujuan dari penelitian ini adalah untuk mempermudah proses penomoran, layanan penyajian, dan mempercepat proses pembuatan laporan arsip berdasarkan kriteria dengan lebig cepat, tepat dan akurat serta menjaga data arsip agar tidak hilang (Basri \& Devitra, 2017), pembuatan aplikasi sistem informasi manajemen surat masuk dan surat keluar dengan menggunakan metode Alphabetical Filing System dan Chronologis System untuk mempermudah proses pencarian surat berdasarkan nama dan tanggal kronologi dan dibangun untuk mempermudah dalam tata kelola arsip sehingga dapat menghemat ruang dan waktu (Diana et al., 2019), membuat aplikasi pengelolaan surat untuk memberikan kemudahan kepada aparatur desa dalam pengelolaan surat.

\section{METODE}

Penelitian ini menggunakan Alphabetical filing system yaitu sistem penyimpanan dan penemuan kembali arsip berdasarkan abjad (Ria Resti, 2020). Metode Chronological filling system merupakan suatu sistem penyimpanan arsiparsip yang di susun berdasarkan waktu seperti tahun, bulan dan tanggal surat. Dalam sistem penyimpanan surat masuk di susun berdasarkan waktu surat di terima sedangkan surat keluar berdasarkan pada waktu surat di buat (Diana et al., 2019), sistem abjad dibutuhkan metode indeks, yaitu cara menemukan dan menentukan ciri/ tanda dari suatu dokumen yang akan dijadikan petunjuk/ tanda pengenal untuk memudahkan mengetahui tempat dokumen tersimpan. Gambar 1 menunjukkan langkah penyusunan arsip dengan Alphabetical Filing System yang sudah sangat lazim ditemui secara konvensional dan dilakukan juga di Kantor Kecamatan Pasar Kemis sebagai tempat penelitian (Ria Resti, 2020).

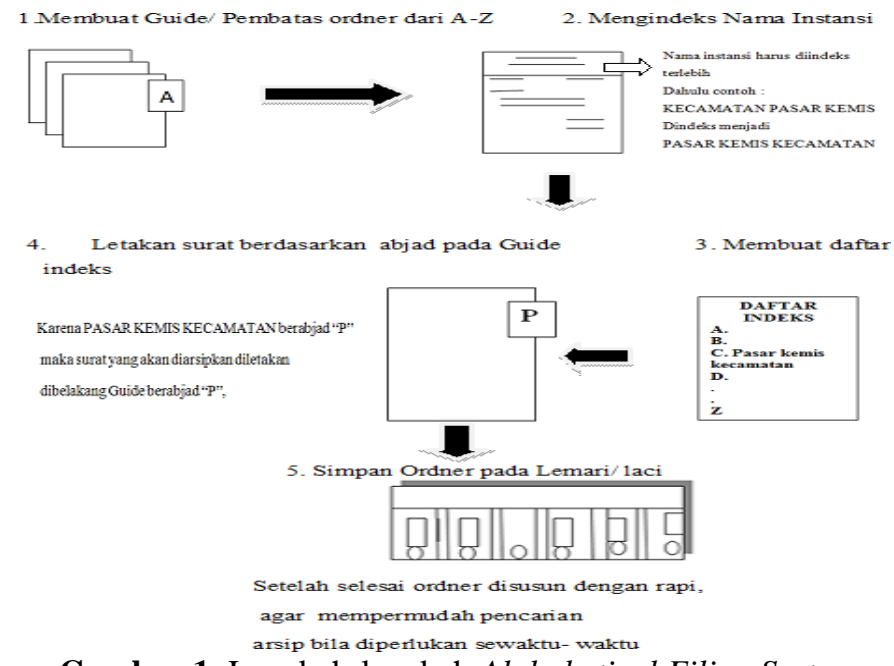

Gambar 1. Langkah-langkah Alphabetical Filing System

(Ria Resti, 2020)

Sistem Kronologis menggunakan kalender sebagai patokan pengindeksan. Langkah- langkah penyimpanan arsip mengunakan metode Chronology System adalah disusun dan diatur berdasarkan waktu, tahun, bulan, dan tanggal penyimpanan arsip (Ria Resti, 2020).

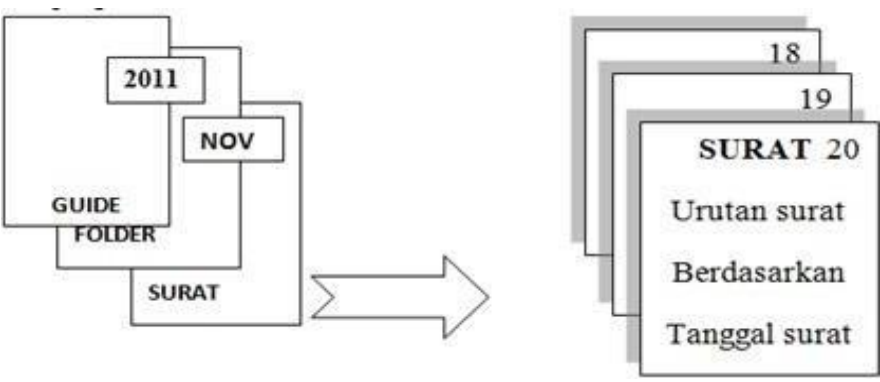

Gambar 2. Langkah-langkah Chronology System(Ria Resti, 2020) 
Noer Azni Septiani dan Deden Haitami, Perancangan Sistem Pengarsipan Surat Masuk dan Surat Keluar pada Desa Kampung Besar Menggunakan Metode Alphabetical Filing dan Chronology System

Chronological filling system yang bertujuan agar setiap pekerjaan bisa dilakukan secara cepat dan mudah dengan hasil yang maksimal dalam hal surat menyurat di dalam instansi dengan mengatur susunan arsip berdasarkan waktu seperti tahun, bulan dan tanggal pada system (Diana et al., 2019).

Adapun metodologi yang penulis gunakan saat ini adalah SDLC karena masih sesuai untuk menjadi pedoman dalam pengembangan system.System Development Life Cycle (SDLC) adalah metodologi yang digunakan untuk mengembangkan, memelihara dan atau mengganti sistem informasi. SDLC terdiri dari tujuh fase atau langkah yaitu dapat dilihat pada gambar 3 sebagai berikut:

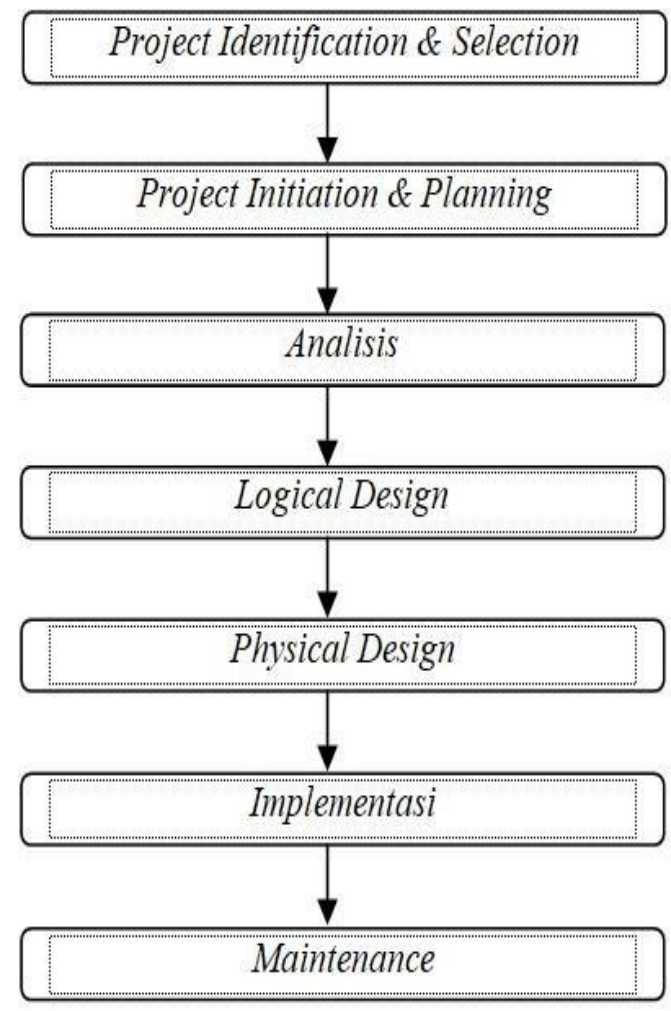

Gambar 3. System Development Life Cycle (SDLC)(Wahyudi, 2020)

Sementara itu guna meningkatkan kinerja system yang tidak terikat oleh jarak dan waktu, maka system yang dibangun adalah berbasis Web(Ria Resti, 2020).

\section{HASIL DAN PEMBAHASAN \\ Use Case}

Analisis pertama dilakukan dengan menerjemahkan hasil observasi system berjalan ke dalam use case. Atas beberapa alasan use case dianggap cukup mudah menerjemahkan kondisi system sehingga dapat diidentifikasi masalah yang muncul maupun potensial masalah. Dengan demikian selanjutnya dapat diusulkan perbaikan system yang efektif untuk membangun system yang sesuai dengan kebutuhan.

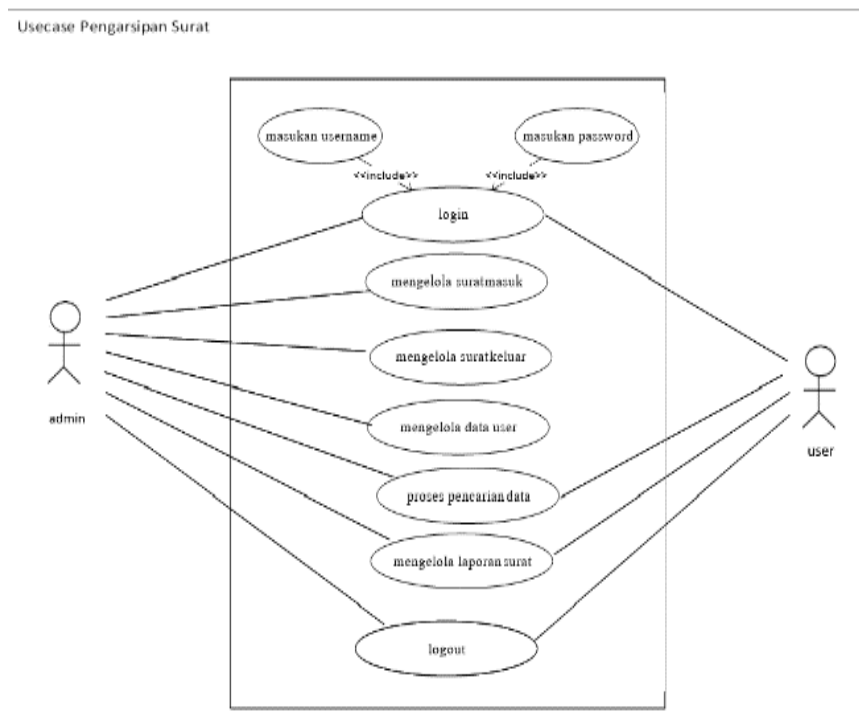

Gambar 4. Use Case Pengarsipan Surat

\section{Tabel Database}

Berikut ini adalah ilustrasi dari tabel yang dibuat untuk mendukung system yang dibangun:

Tabel 1. Rancangan Table Surat Masuk

\begin{tabular}{llllll}
\hline No & $\begin{array}{l}\text { Elemen } \\
\text { Data }\end{array}$ & Nama Field & Tipe & Size & Keterangan \\
\hline 1 & Usename & Username & Varchar & 20 & Primary key \\
2 & Nama & Nama & Varchar & 20 & \\
3 & Password & Password & Varchar & 15 & \\
4 & Status & Status & Varchar & 15 & \\
5 & No telepon & No_telp & Varchar & 13 & \\
6 & Alamat & Alamat & Varchar & 50 & \\
7 & Email & Email & Varchar & 20 & \\
8 & Jenis & Jns_kel & Varchar & 10 & \\
& kelamin & & & & \\
\hline
\end{tabular}

Tabel 2. Rancangan Table Surat Keluar

\begin{tabular}{llllll}
\hline No & Elemen data & Nama field & Tipe & size & Ket. \\
\hline 1 & No_srt_keluar & No_srt_keluar & Varchar & 30 & $\begin{array}{l}\text { Primary } \\
\text { key }\end{array}$ \\
2 & Jenis surat & Jns_srt & Varchar & 15 & \\
3 & Tanggal surat & Tgl_srt & Date & & \\
4 & Tanggal Keluar & Tgl_keluar & Date & & \\
5 & Penerima & Penerima & varchar & 20 & \\
6 & Perihal & Perihal & varchar & 80 & \\
7 & Arsip & Arsip & varchar & 15 & \\
8 & gambar & Gambar & varhar & 30 & \\
\hline
\end{tabular}

Tabel 3. Rancangan Table Admin

\begin{tabular}{llllll}
\hline No & Elemen & Nama Field & Tipe & Size & Keterangan \\
& Data & & & & \\
\hline 1 & Nomor & no_srt_msk & Varchar 30 & Primary key \\
2 & Jenis surat & jns_srt & Varchar & 20 & \\
3 & Tgl surat & Tgl_srt & Date & & \\
4 & Tgl masuk & Tgl_msk & Date & & \\
5 & Asal surat & Asal_srt & Varchar 30 & \\
6 & tujuan & Tujuan & Varchar 30 & \\
7 & perihal & Perihal & varchar 80 & \\
8 & arsip & Arsip & varchar 15 & \\
9 & gambar & Gambar & varchar 30 & \\
\hline
\end{tabular}


Noer Azni Septiani dan Deden Haitami, Perancangan Sistem Pengarsipan Surat Masuk dan Surat Keluar pada Desa Kampung Besar Menggunakan Metode Alphabetical Filing dan Chronology System

\section{GUI}

Graphical User Interface (GUI) memang penting diperhatikan untuk memberikan pengalaman yang menarik dan user friendly sesuai hasil analisis yang dijalankan sebelumnya. Namun dalam peneliian ini GUI didesain cukup sederhana mengingat informasi yang ditampilkan belum begitu kompleks.

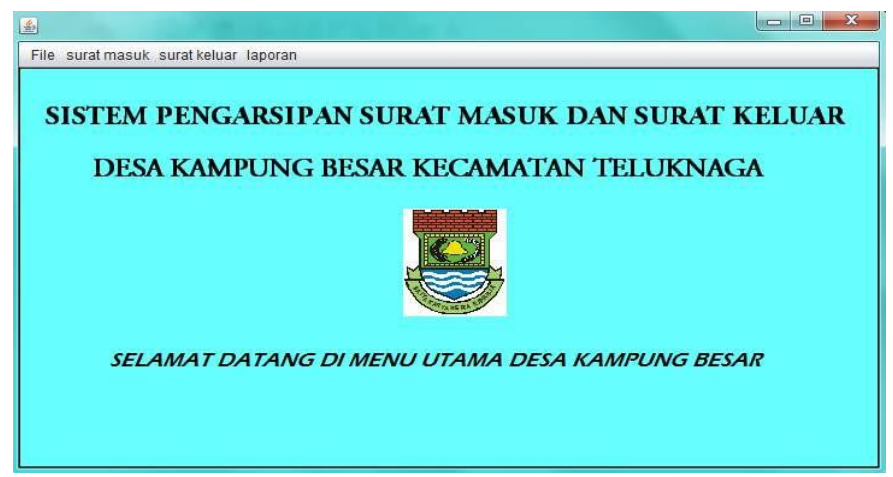

Gambar 5. Rancangan GUI Menu Utama

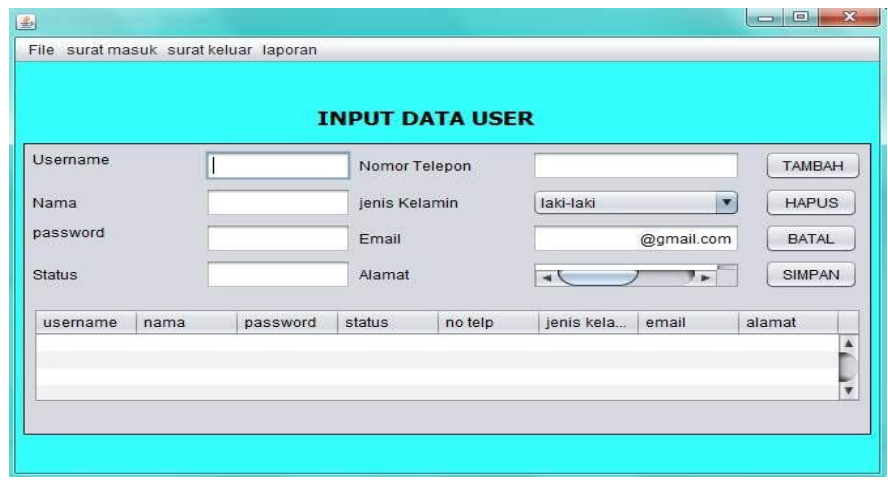

Gambar 6. Rancangan GUI Data User

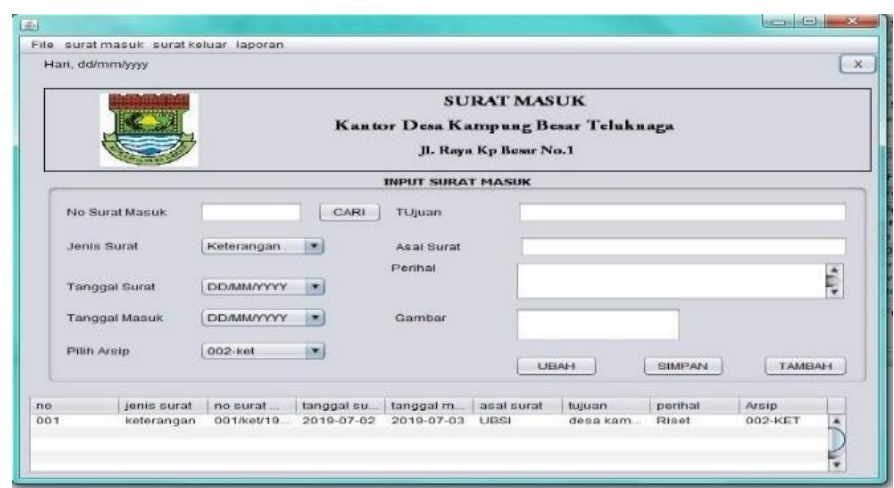

Gambar 7. Rancangan GUI Surat Masuk

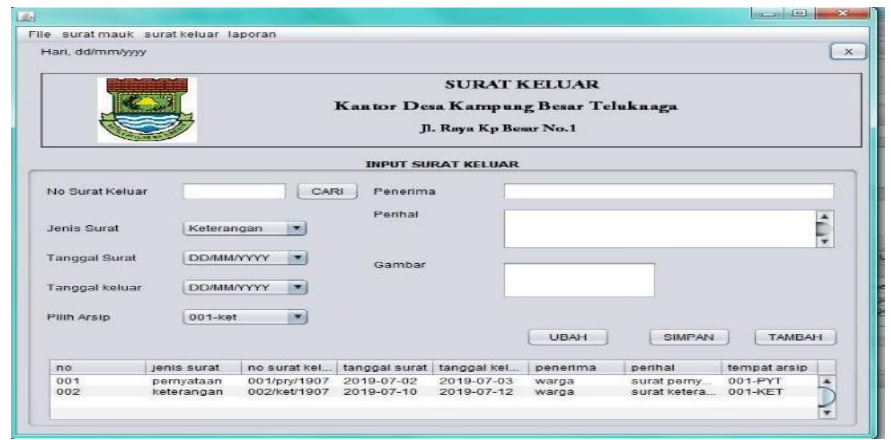

Gambar 8. Rancangan GUI Surat Keluar

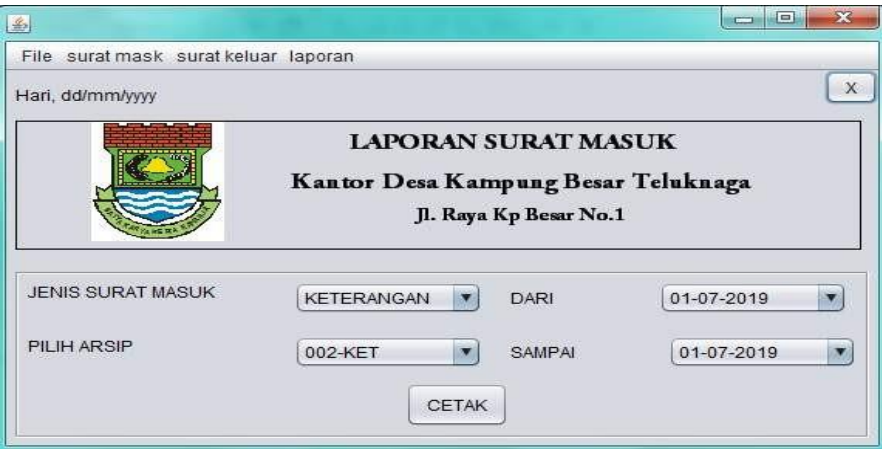

Gambar 9. Rancangan GUI Laporan Surat Masuk

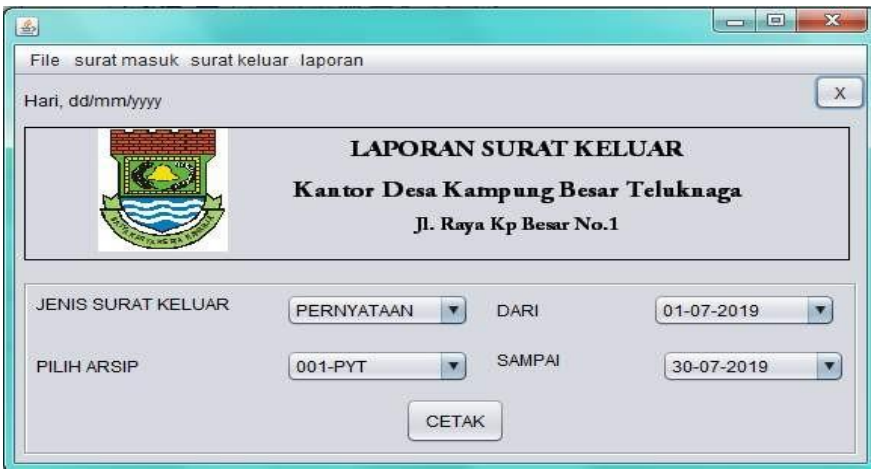

Gambar 10. Rancangan GUI Laporan Surat Keluar

\section{SIMPULAN}

Perancangan sistem pengarsipan surat masuk dan surat keluar pada desa kampung besar dengan menggunkan sistem informasi pengarsipan surat masuk dan surat keluar ini maka proses pencarian data surat masuk dan surat keluar akan menjadi lebih cepat karena data-data sudah tersimpan dengan aman dan terstruktur, sehingga tidak terjadi lagi keterlambatan dalam pencarian data,dengan adanya sistem pengarsipan surat masuk dan surat keluar yang berbasis komputerisasi sehingga dapat meningkatkan produktifitas kerja khususnya dari segi proses pencarian data surat masuk dan surat keluar serta pembuatan laporan akan menjadi cepat dan akurat,memudahkan staff desa dalam melakukan proses penginputan surat masuk dan surat keluar serta proses pembuatan laporan,mempermudah warga dalam mengajukan dan mendapatkan surat secara cepat, terutama dalam pencetakan ulang surat karena data-data sudah tersimpan oleh sistem.

\section{DAFTAR PUSTAKA}

Anggraeni, D., \& Iriani, S. (2013). Sistem Informasi Pengarsipan Surat Masuk Dan Surat Keluar Pada Kantor Kecamatan Pringkuku. Indonesian Journal on Networking and Security.

Basri, \& Devitra, J. (2017). Analisis Dan Perancangan Sistem Informasi Pengelolaan Arsip Berbasis Web (Studi Kasus: Pada Komisi Pemilihan Umum (Kpu) Kabupaten Tebo. Jurnal Manajemen Sistem Informasi, 2(1), 227-243. https://doi.org/http://dx.doi.org/10.1159

Diana, I. N., Anwar, M. M., N, R. S., \& D, I. G. S. M. 
(2019). Analisis Perancangan Sistem Informasi Pengarsipan Dan Disposisi Surat Berbasis Chronological Filling System. September, 27-32. http://santika.ijconsist.org/index.php/SANTIKA/a rticle/view/11/10

Farell, G., Saputra, H. K., \& Novid, I. (2018). Rancang Bangun Sistem Informasi Pengarsipan Surat Menyurat (Studi Kasus Fakultas Teknik Unp). Jurnal Teknologi Informasi Dan Pendidikan (JTIP).

Mayasari, M. S., Andrika, Y., Fitriyani, F., \& Zailun, Z. (2020). OPTIMALISASI APLIKASI SURAT MENYURAT PADA PT. BPR SENTRAL MITRA SEJAHTERA (SMS) SUNGAILIAT. Simetris: Jurnal Teknik Mesin, Elektro Dan Ilmu Komputer. https://doi.org/10.24176/simet.v11i1.3874

Mulyati, M., Sany, N., \& Kurniawan, M. (2020). Sistem Informasi Surat Masuk Pada Pengelolaan Rantai Suplai Satuan Kerja Khusus Migas. Technomedia Journal, 5(1), 27-39. https://doi.org/10.33050/tmj.v5i1.1256

Pawana, M. G., Suharsono, N., \& Kirna, I. M. (2014). Pengembangan Multimedia Interaktif Berbasis Proyek Dengan Model ADDIE Pada Materi Pemrograman Web Siswa Kelas X Semester Genap Di SMK Negeri 3 Singaraja. E-Journal Program Pascasarjana Universitas Pendidikan Ganesha.

Ria Resti, E. a. (2020). SISTEM PENGELOLAAN DOKUMEN SURAT MENGGUNAKAN METODE ALPHABETICAL FILING DAN CHRONOLOGY SYSTEM. 15, 192-200.

Simangunsong, A. (2018). Sistem Informasi Pengarsipan Dokumen Berbasis Web. Sistem Informasi Pengarsipan Dokumen Berbasis Web, 2(1), 11.

Wahyudi, S. (2020). PENGEMBANGAN SISTEM INFORMASI KLINIK BERBASIS WEB ( Studi Kasus : Klinik Surya Medika Pasir Pengaraian ). Riau Journal OfComputer Science, 06(01), 50-57.

Wati, M., \& Despahari, E. (2018). Sistem Informasi Pelayanan Administrasi Kependudukan Dan Catatan Sipil Kelurahan Di Kecamatan Marangkayu Kutai Kartanegara. Jurnal Rekayasa Teknologi Informasi. https://doi.org/10.30872/JURTI.V2I1.1379 